\title{
Algunas vicisitudes del proceso monitorio en Colombia: una visión desde la academia
}

\author{
Amalia Tapias-Tapias * \\ Rafael Evelio Muñoz-Sánchez ${ }^{\star *}$ \\ Rafael Ricardo Latorre-Merchán ${ }^{\star * *}$
}

\footnotetext{
Magíster en Administración. Profesora investigadora, Universidad Cooperativa de Colombia, sede Bucaramanga, Colombia. Correo electrónico: amalia.tapias@campusucc.edu.co.

** Estudiante de Derecho, Universidad Cooperativa de Colombia, sede Bucaramanga, Colombia. Correo electrónico: rafael.munoz@campusucc.edu.co

*** Estudiante de Derecho, Universidad Cooperativa de Colombia, sede Bucaramanga, Colombia. Correo electrónico: rafael.latorrem@campusucc.edu.co
}

Recibido: 2 de diciembre del 2015 Aprobado: 10 de agosto del 2016

Cómo citar este artículo: Amalia TapiasTapias, Rafael Evelio Muñoz-Sánchez, Lili Medina-Ortiz. Algunas vicisitudes del proceso monitorio en Colombia: una visión desde la academia. DIXI 24. Octubre 2016. Pág. 49. doi: http://dx.doi.org/10.16925/ di.v18i24.1522

\section{Resumen}

Introducción: resultado de la investigación desarrollada por el semillero de Derecho Procesal de la Universidad Cooperativa de Colombia (UCC), sede Bucaramanga. Metodología: analizar algunas vicisitudes del nuevo proceso declarativo monitorio, el cual, en hora buena, introdujo el Código General del Proceso (CGP) al ordenamiento jurídico. Estas vicisitudes están relacionadas con la tipología, la buena fe del acreedor, el agotamiento del requisito de procedibilidad y la procedencia de medidas cautelares. El análisis se realiza con fundamentos en los artículos 419 al 421 y 590 del CGP, la Ley 640 del 2001, la Sentencia C-726 de 2014 de la Corte Constitucional y la teoría de Calamandrei acerca del proceso monitorio. Resultados: el legislador le ha dado el mismo tratamiento procesal al proceso monitorio puro y al documental, contrario a la teoría de Calamandrei; la admisión del proceso monitorio puro implica que el juez apoye el requerimiento de pago en la buena fe del acreedor. Al tenor de las normas relativas a la conciliación pre-procesal, para iniciar un proceso monitorio, clasificado como declarativo especial, el demandante deberá acreditar el cumplimiento del requisito de procedibilidad, esto es, aportar prueba de haber agotado el intento de conciliación. No obstante, podrá suplirlo con la solicitud y lógicamente con la procedencia de una medida cautelar, para lo cual tendrá que prestar caución. Conclusiones: en el proceso monitorio, el demandante debe aportar prueba del agotamiento del requisito de procedibilidad. Encontrar una medida innominada en el contexto del proceso monitorio, en aras de garantizar la efectividad del derecho al crédito, será una ardua tarea.

Palabras clave: buena fe, celeridad, medida cautelar innominada, proceso declarativo monitorio. 


\title{
Aspects of Small Claims Procedure in Colombia: A View from the Academy
}

\begin{abstract}
Introduction: This article is the result of research carried out by the research incubator of Procedural Law of the Bucaramanga Campus of the Universidad Cooperativa de Colombia (UCC). Methodology: Analysis of certain aspects of the new small claims procedure for declaratory judgment, which the General Procedure Code (CGP by its Spanish initials) successfully introduced into the legal system. These aspects are related to type, good faith of the creditor, exhaustion of procedural requirements, and propriety of interim measures. The analysis was performed pursuant to Articles 419 to 421 and 590 of the CGP, Law 640 of 2001, Decision C-726 of 2014 of the Constitutional Court of Colombia, and Calamandrei's theory on small claims procedure. Results: The legislature has shown the same procedural treatment to both pure and documentary small claims procedure, contrary to Calamandrei's theory; the admission of pure small claims procedure implies that the judge supports the requirement of good faith payment to the creditor. In accordance with the norms on pre-trial conciliation, to initiate a small claims procedure classified as special declaratory, the plaintiff must prove compliance with the procedural requirements, that is, provide proof of having exhausted the attempt at conciliation. However, the plaintiff may substitute this with the request for and, logically, with the propriety of an interim measure, for which security must be furnished. Conclusions: In small claims procedure, the plaintiff must provide proof of having exhausted procedural requirements. Finding an innominate measure in the context of small claims procedure with a view to guaranteeing the effectiveness of the right to credence will be a difficult task.
\end{abstract}

Keywords: good faith, promptness, innominate interim measure, small claims procedure for declaratory judgment

\section{Algumas vicissitudes do processo monitório na Colômbia: uma visão da academia}

\section{Resumo}

Introdução: resultado da pesquisa desenvolvida pelo grupo de pesquisa de Direito Processual da Universidad Cooperativa de Colombia (UCC), sede Bucaramanga. Metodologia: analisar algumas vicissitudes do novo processo declarativo monitório, o qual, em tempo oportuno, introduziu o Código Geral do Processo (CGP) ao ordenamento jurídico. Essas vicissitudes estão relacionadas com a tipologia, com a boa-fé do credor, com o exaurimento do requisito de procedibilidade e com a procedência de medidas cautelares. A análise realiza-se com fundamentos nos artigos 419 ao 421 e 590 do CGP, a Lei 640 de 2001, a Sentença C-726 de 2014 da Corte Constitucional e a teoria de Calamandrei acerca do processo monitório. Resultados: o legislador deu o mesmo tratamento processual ao processo monitório puro e ao documental, ao contrário da teoria de Calamandrei; a admissão do processo monitório puro implica que o juiz apoie o requerimento de pagamento na boa-fé do credor. Segundo as normas relativas à conciliação pré-processual, para iniciar um processo monitório, classificado como declarativo especial, o requerente deverá comprovar o cumprimento do requisito de procedibilidade, isso é, provar ter exaurido a tentativa de conciliação. No entanto, poderá complementar com a solicitação e logicamente com a procedência de uma medida cautelar, para o qual terá que prestar caução. Conclusões: no processo monitório, o requerente deve provar o exaurimento do requisito de procedibilidade. Encontrar uma medida inominada no contexto do processo monitório, a fim de garantir a efetividade do direito ao crédito, será uma árdua tarefa.

Palavras-chave: boa-fé, celeridade, medida cautelar inominada, processo declarativo monitório. 


\section{INTRODUCCIÓN}

Un sin número de comentarios se han hecho en torno al Código General del Proceso (CGP), aquel estatuto que colmará la necesidad latente de una administración de justicia eficaz. Este código conlleva una serie de cambios en la estructura de los procesos y la innovación en otros institutos, los cuales resultan ser muy interesantes, entre los que se encuentra el proceso monitorio.

El proceso monitorio se ha considerado en Colombia como la joya de la corona. Aún sin entrar en vigencia, despierta gran polémica por su celeridad y aparente vulneración del derecho a la igualdad y al debido proceso, contrapuestos a los derechos a la tutela judicial efectiva y al de crédito, que le asiste a los acreedores desprovistos de un título ejecutivo.

Este artículo aborda el análisis del proceso monitorio puro en Colombia desde algunos de los elementos que son determinantes en la admisión, el desarrollo y efectividad del mismo: la buena fe del acreedor como fundamento para proferir el requerimiento de pago, las pruebas, el requisito de procedibilidad y las medidas cautelares. Realiza un recorrido corto por los albores del CGP y de la génesis del proceso monitorio en otras latitudes, pasando por la tipología del proceso monitorio propuesta por Calamanderi, y examina el CGP de Colombia en los capítulos correspondientes a las pruebas y a las medidas cautelares.

El resultado más importe de la construcción de este documento se materializa en el interés que despertó el tema al interior del grupo de semillero de investigación, al estudiar y discurrir sobre los escritos de autores nacionales e internacionales, tales como Francesco Carneluti, Piero Calamandrei, Juan Pablo Correa-Delcasso, Jordi Nieva-Fenoll, Jairo ParraQuijano, Manuel Enrique Rojas-Gómez, entre otros. Así mismo, de navegar por la Sentencia C-726 de 2014, mediante la cual la Corte Constitucional declara exequible los Artículos 419 y 421 del CGP, al ser acusados por la aparente - a primera vista - vulneración de los derechos a la igualdad y al debido proceso.

\section{Algunas Vicisitudes Del PROCEso MONITORIO PURO EN COLOMBIA}

En hora buena, el legislador colombiano profiere el Código General del Proceso (CGP), mediante la Ley 1564 del 2012. Esto con fundamento en los resultados de la tarea que inició el Instituto Colombiano de Derecho Procesal (ICDP) en el 2003': la construcción de un nuevo ordenamiento procesal civil, cuya finalidad, entre otras ${ }^{2}$, es la adecuación de las normas procesales a la Constitución Política de 1991 y a la jurisprudencia, tanto de la Corte Constitucional, como de la Sala de Casación Civil de la Corte Suprema de Justicia ${ }^{3}$.

Parafraseando la exposición de motivos del proyecto de ley en mención, se tiene que el nuevo estatuto se caracteriza por buscar la celeridad de todos los procesos judiciales con observancia de las garantías procesales, en aras de obtener una sentencia justa y pronta $^{4}$; para lo cual, trae consigo un número significativo de cambios y de novedosas instituciones, tales como el término máximo de duración del proceso (Art. 121), el saneamiento de vicios en cada etapa del proceso (Art. 132), las pruebas de oficio (Art. 170), las medidas cautelares innominadas (Art. 377, Art. 590-1-c), el juramento estimatorio sobre el quantum de las pretensiones (Art. 206), la reducción de clases de procesos y la inclusión de un nuevo proceso en los declarativos especiales denominado "monitorio" (Artículos 419, 420 y 421).

En el CGP se estructuran cuatro tipos de procesos: 1. Procesos declarativos (Artículos 368 al 421); 2. Procesos ejecutivos (Artículos 422 al 472); 3. Procesos de liquidación (Artículos 473 al 576); y 4. Procesos de jurisdicción voluntaria (Artículos 577 al 587). A su vez, los procesos declarativos se clasifican así: 1. Proceso verbal (Artículos 368 al 389); 2. Procesos verbal sumario (Artículos 390 al 398); 3. Procesos especiales (Artículos 399 al 421). En estos últimos se subsumen los procesos de expropiación, deslinde y amojonamiento, divisorio y monitorio. $Y$ es precisamente este último proceso en el que se centra la atención de este artículo.

Delcasso, como se citó en Parra, define el proceso monitorio como un "proceso especial plenario rápido que tiende, mediante la técnica de la inversión de la iniciativa del contradictorio, a la rápida creación de un título ejecutivo con plenos efectos de cosa juzgada

\footnotetext{
Véase http://www.icdp.org.co/publicaciones/codigoGeneralDelProceso.html

2 Ley 1564 de 2012. Por medio de la cual se expide el Código General del Proceso y se dictan otras disposiciones. Julio 12 del 2012. Do 48489. Artículos 2 al 14.

3 Véase Corte Constitucional de Colombia. Sentencia C-726/14. (MP Martha Victoria Sáchica Méndez, septiembre 24 del 2014).

4 Véase Instituto Colombiano de Derecho Procesal. Proyecto de Código General del Proceso, Exposición de motivos. Disponible en http://www.icdp.org.co/descargas/cgp/Exposicion Motivos.pdf
} 
en aquellos casos que determine la Ley"5. De igual forma, Picó i Junoy lo define como un "proceso declarativo plenario especial caracterizado por la inversión del contradictorio"6, precisando que es declarativo porque persigue la obtención del título ejecutivo; plenario porque la sentencia o resolución de juez, en caso de guardar silencio el requerido, pone fin al asunto con efectos de cosa juzgada; especial porque sirve para la tutela del crédito; y su característica principal (inversión del contradictorio), solo existe en caso de oposición del deudor ${ }^{7}$. Por su parte, Calamandrei define el proceso monitorio como "aquel en el que, en virtud de la simple petición escrita del acreedor, el Juez competente libra, sin oír al deudor, una orden condicionada de pago dirigida al mismo"s, concepto referenciado por la Corte Constitucional en la Sentencia C-726 del 2014.

En la precitada sentencia, la Corte Constitucional define el proceso monitorio:

Un proceso declarativo de naturaleza especial dirigido a que los acreedores de obligaciones en dinero de mínima cuantía, que carezcan de título ejecutivo puedan hacerlas exigibles de manera célere y eficaz, sustrayéndose de los formalismos procedimentales que ordinariamente extienden de manera innecesaria la duración de un proceso judicial? 9

Definición esta que el Alto Tribunal deduce a partir de la explicación de la naturaleza jurídica del proceso monitorio, plasmada en la ponencia del primer debate de proyecto de Ley número 159 del 2011 del Senado de la República, y 196 del 2011 de la Cámara de Representantes.

\section{A. Sucinta génesis del proceso monitorio}

Ahora bien, a fin de adentrarse en el estudio de las vicisitudes del proceso monitorio en Colombia, es importante recordar someramente su génesis, la cual, según el doctor Jordi Nieva-Fenoll ${ }^{10}$, no se ha deter-

5 Véase Jairo Parra-Quijano. Prólogo. El Procedimiento MONITORIO EN AMÉRICA LATINA: PASADO, PRESENTE Y FUtURO. Temis. (2013). Pág. IX.

6 Véase Joan Picó i Junoy. El proceso monitorio UNA VISIÓN ESPAÑOLA Y EUROPEA DE LA TUTELA RÁPIDA DEL CRÉDITO. Disponible en http://www.icdp.org.co/revista/articulos/37/ JoanPicoIJunoy.pdf

7 Id. Pág. 4.

8 Cf. Corte Constitucional de Colombia, supra, nota 3.

$9 \quad$ Id.

10 Véase Jordi Nieva-Fenoll. Aproximación al origen del procedimiento monitorio. El PROCEDIMIENTo MONITORIo EN AMÉRICA Latina. Pasado, presente y futuro. Temis. (2013). Pag. 2-16. minado con exactitud. En un recorrido rápido por la historia, Nieva-Fenoll ubica los remotos orígenes del proceso monitorio en el Edicto Rotario del pueblo Longobardo en Italia, así como señala algunos vestigios en el Derecho hebreo. Avanza este autor por la fase previa del proceso romano posclásico, acercándose a la Litis denunciatio ${ }^{11}$, la cual fue derogada para dar paso al "proceso de libelo", que corresponde a la fase previa del solemnis ordo iudiciarius ${ }^{12}$. Este, a su vez, evolucionó al preceptum o mandatum de solvendo cum clausula iustificativa del Derecho medieval italiano, del cual parece provenir el proceso monitorio contemporáneo ${ }^{13}$. El proceso monitorio fue concebido como una acción rápida, contraria al proceso ordinario medieval, con una estructura perfectamente delimitada ${ }^{14}$.

11 Nieva-Fenoll afirma: "la litis denunciatio era un escrito de la parte actora en editio actionis; lo que, sin duda, simplificaba la redacción del mismo. Dicho escrito era notificado por el juez a la parte demandada, notificación tras la que se abría un plazo de cuatro meses para comparecer ante el juez. Existían hasta tres intentos de notificación al demandado mediante edictos, tras los cuales, si no eran atendidos, resultaba condenado". Id. Pág. 9.

12 De acuerdo con Nieva-Fenoll, "en dicho proceso se iniciaban las actuaciones con un libellus conventionis. En este libelo, el actor exponía simplemente su petición (postulatio simplex), sí como los hechos esquemáticos en que se basaba, pero sin explicar en absoluto los motivos de su solicitud. El juez examinaba el escrito sumariamente y emitía una sentencia (lógicamente interlocutoria) en la que ordenaba la notificación del demandado para que compareciera, no ya en el plazo de cuatro meses, sino en un término mucho más breve según lo que hubiera solicitado el demandante. En este plazo, si el demandado, si pensaba oponerse, debía presentar el libellus contradictorii, junto con la presentación de una caución que garantizaba su continuada comparecencia en el proceso. Como puede suponerse, dicho libellus contradictorii tampoco debía ser motivado, bastando con la expresión del demandado de que pensaba oponerse. La motivación de ambas posiciones se hacía ya en la fase siguiente, tras el libellus contradictorii. El demandado, no obstante, continuaba debiendo ser citado por tres veces por edictos, si no había comparecido. Y como sucedía en el procedimiento de la cognitio, era también condenado si no comparecía tras ese edictum peremptorium. Id. Págs. 9-10.

13 Véase Juan Pablo Correa-Delcasso. El proceso monitorio en el derecho comparado: diez puntos clave para su correcta implementación y desarrollo en los países de América Latina. EL PROCEDImiento monitorio en América Latina. Pasado, presente y FUturo. Temis. (2013). Págs.17-55.

14 Correa-Delcasso cita a Gutiérrez-Alviz al respecto: "Se iniciaba con una orden del juez de pagar o hacer alguna cosa (de solvendo vel trahendo). Esta orden o mandato venía emanada sin una previa cognición (ante causa cognitionem). Las posibles objeciones a la admisibilidad del proeceptum o mandatum derivantes de la falta de cognición previa, venían resueltas con la justificación que el proceso recibe de la cláusula que en él se contiene (si senseris reus te gravatum, compareas coram nobis complementatum iustitutioe recepturus). En razón de esta cláusula, el curso del procedimiento podía llegar a estos dos resultados opuestos; o el deudor intimado no comparecía, y entonces el mandato se confirmaba pasando en 
Giovenda, citado por Gómez-Orozco, afirma que el proceso monitorio, gracias a su estructura reducida de trámites y exigencias, es el mecanismo eficaz para resolver controversias de naturaleza civil o mercantil, y surge como producto de la evolución de las normas e instituciones del Derecho romano ${ }^{15}$.

Así, el Derecho medieval italiano es la cuna del proceso monitorio, el cual más tarde fue introducido en el Derecho germánico, constituyéndose este último en el modelo a seguir por otros ordenamientos jurídicos, e.g. España, Francia y Austria, en el antiguo continente; Honduras, Uruguay, Chile, Venezuela y Colombia, en Latinoamérica; y con amplia aceptación y eficacia en la Unión Europea.

\section{B. Tipología del proceso monitorio según Piero Calamandrei}

Es importante citar al célebre profesor Piero Calamandrei, quien a partir de sus estudios acerca de este proceso especial, concluye que existen dos tipos de proceso monitorio: documental y puro. El primero se caracteriza esencialmente en que el acreedor debe aportar un documento justificativo con el escrito de petición inicial; y el segundo, el puro, en que el juez profiere requerimiento de pago con fundamento en la sola afirmación unilateral y no probada del acreedor $^{16}$. En España, Italia y Francia, se tiene que el proceso monitorio responde al tipo documental; entre tanto, en Alemania y la Unión Europea, al puro.

Exactamente en este punto es necesario traer a colación los argumentos en los cuales Calamandrei funda dicha tipología, tal como se citan en Correa ${ }^{17}$. Allí expone como en el proceso monitorio puro, "la orden condicionada de pago se libra por el juez a base de la sola afirmación, unilateral y no probada, del acreedor". Así mismo, afirma:

La simple oposición no motivada del deudor hace caer en la nada la orden de pago, de manera que el juicio en contradictorio, que puede eventualmente desarrollarse en mérito de tal oposición, no se diri-

autoridad de cosa juzgada, o bien el deudor comparecía, y entonces su sola comparecencia hacía que el procedimiento especial cesara, teniéndose que seguir los trámites del juicio ordinario". Id. Pág. 22. 15 Véase Jose Alejandro Gomez-Orozco. Introducción AL PROCESO MONITORIO COLOMBIANO. CONSTITUCIONALIDAD Y ORALIDAD DEL DERECHO CIVIL. Librería Jurídica Sánchez R. Ltda. (2014). Pag. 56.

16 Véase Juan Pablo Correa-Delcasso, supra, nota 13. Pág. 24.

17 Id. Pág 21 ge a decidir si la orden de pago debe ser revocada o mantenida, sino a decidir ex novo sobre la originaria acción de condena.

Paralelamente, afirma que en el proceso monitorio documental, "el mandato de pago presupone que los hechos constitutivos de crédito sean probados mediante documentos". De igual forma, asevera:

La oposición del deudor no hace caer sin más el mandato de pago, pero tiene en cambio, el efecto de abrir un juicio de cognición en contradictorio, en el cual el tribunal, valorando en sus elementos de derecho y de hecho las excepciones del demandado, debe decidir si estas son tales que demuestren la falta de fundamento del mandato de pago o si, por el contrario, este merece, a base de las pruebas escritas ya proporcionadas por el actor, ser, sin embargo, mantenido y hecho ejecutivo ${ }^{18}$.

De acuerdo con la caracterización que realiza Calamandrei del proceso monitorio puro, el ejemplo exacto de este tipo de proceso se encuentra reglamentado en la serie de artículos que va del 688 al 703 de la Legislación Procesal Civil Alemana (zPo por sus siglas en alemán), así como en la de Austria y Suecia, así como en el Reglamento de la Unión Europea ${ }^{19}$, en

\section{Id. Pág. 21}

19 El proceso monitorio para la Unión Europea, instituido según Reglamento N. ${ }^{\circ} 1896$ del 2006, nace con el objeto de simplificar, acelerar y reducir los costes de litigación en asuntos transfronterizos relativos a créditos pecuniarios y a permitir la libre circulación de requerimientos europeos de pago a través de todos los Estados miembros. Cf. EurLex. "Reglamento de la Unión Europea”. Disponible en http://europa.eu/legislation_summaries/ justice_freedom_security/judicial_cooperation_in_civil_matters/ 116023 es.htm Este proceso monitorio solo puede utilizarse para créditos pecuniarios de importe determinado, vencidos y exigibles en la fecha en que se presente la petición. Sin límite de cuantía, exceptuando lo establecido en el artículo segundo del reglamento, la petición debe formularse a través de los formatos establecidos. Sin embargo, los órganos jurisdiccionales deberán tener en cuenta cualquier otra forma escrita en la que se presente la solicitud o su oposición, siempre y cuando cumpla con los requisitos mínimos establecidos en el artículo 7 del reglamento en caso del peticionario y los requisitos del artículo 16 del reglamento para el caso de oposición. Cf. también Red Judicial Europea en Materia Civil y Mercantil. GuÍA PRÁCTICA PARA LA APLICACIÓN DEL REGLAMENTO relativo Al proceso monitorio europeo. Pág. 6. Disponible en http://ec.europa.eu/civiljustice/publications/docs/guide_european_enforcement_orde r_es.pdf

Una vez realizada la petición monitoria, el órgano jurisdiccional realiza un breve análisis de los requisitos mínimos para corroborar que la petición se encuentra debidamente fundada. Prosigue con la expedición del requerimiento europeo de pago, el cual debe cumplir con lo establecido en el artículo 12 del reglamento, para 
los cuales el requerimiento de pago pierde su fuerza ante la oposición del deudor, aun sin la manifestación de las razones en la que se fundamente. Situación que exige del acreedor sustentar su pretensión en un escrito de demanda según formatos preestablecidos por el legislador, de manera que sea posible continuar con el proceso. Esto, según Poveda:

En caso de oposición del demandando contra el mandamiento de pago librado por el juez, el proceso monitorio termina brindándole al actor la oportunidad de iniciar un nuevo juicio declarativo de conformidad con los criterios o reglas establecidas para la determinación de la competencia en cada uno de los Estados $^{20}$.

Contrario sensu, la caracterización que hace el mismo autor del proceso monitorio documental se halla en el ordenamiento procesal civil de España, Francia e Italia, entre otros. Este modelo migró a diferentes países latinoamericanos de tal modo que en este proceso, "la prueba documental se convierte en elemento necesario e imprescindible de la petición monitoria"21. Así mismo, en caso de oposición del deudor,

El efecto que se produce es la remisión a que en un proceso declarativo común se resuelva el asunto; $y$, en

dar paso a la notificación. Dicha notificación debe estar en conformidad con la filosofía que pregona el considerando N. ${ }^{\circ} 20$ del reglamento: "todos los métodos de notificación enumerados en los artículos 13 y 14 se caracterizan por ofrecer bien una certidumbre total (artículo 13) o bien un alto grado de probabilidad (artículo 14) de que el documento notificado ha sido recibido por su destinatario"; no sin antes aclarar que,"ningún método de notificación que se base en una ficción legal del cumplimiento de estas normas mínimas deben considerarse suficiente". Efectuada la notificación en los términos de ley, el demandado cuenta con treinta días para tomar una de las siguientes posturas: 1. Pagar al demandante el importe indicado en el requerimiento, lo cual pone fin al proceso monitorio; 2. Guardar silencio, lo cual acarrea la sanción estipulada en el artículo 18, que impone la ejecutividad del requerimiento de pago, la cual textualmente dice: "Si en el plazo establecido en el artículo 16 , apartado 2 , teniendo en cuenta un periodo de tiempo apropiado para que sea posible la recepción del escrito, no se ha presentado ningún escrito de oposición ante el órgano jurisdiccional de origen, este declarará ejecutivo sin demora el requerimiento europeo de pago." Id. Art. 16. 4. Presentar oposición en el término adecuado, a través del respectivo formato o con cualquier otro método idóneo. Cabe resaltar que la norma específica en su artículo 16, apartado 3, dice lo siguiente: "El demandante deberá indicar en su escrito de oposición que impugna la deuda, sin que esté obligado a motivarlo". 20 Véase Abelardo Poveda. Manuel del proceso monitorio. Modelo documental español. Ediciones del Profesional Ltda. (2006). Pág. 29.

21 Id. Pág. 30. caso de no pagar y de no realizar la oposición argumentada contra dicha resolución, el auto de mandamiento adquiere firmeza y se constituye como título de ejecución ${ }^{22}$.

A partir de la tipología del proceso monitorio que define Calamandrei, surge el siguiente interrogante: ¿La estructura del proceso monitorio que introduce el CGP en el ordenamiento jurídico colombiano, corresponde a la del monitorio puro definido por Calamandrei? Una respuesta a esta cuestión forja el siguiente análisis.

\section{Análisis de la tipología del proceso monitorio en Colombia}

Algunos autores afirman que el proceso monitorio en Colombia es puro. Entre estos, Gómez-Orozco:

El procedimiento monitorio acogido en Colombia es un procedimiento de tipo puro y limitado, toda vez que el hecho de que el acreedor aporte los documentos que soportan la obligación es contingente, es decir, puede que los tenga y los aporte frente a la solicitud que hace al juez, o en el evento de no poseer tales documentos (...) deberá señalar dónde está, o manifestar bajo juramento que se entiende prestado con la presentación de la demanda, que no existen soportes documentales. ${ }^{23}$

Así como el autor precitado, la Corte Constitucional, al desarrollar el acápite de consideraciones de la Sentencia C-726 del 2014, da a entender que se trata de un proceso monitorio puro:

8.6. sobre este punto se impone una consideración adicional, la configuración técnica del proceso monitorio está soportada en doble vía en el principio de la buena fe, ya que la orden de pago emitida por el juez surge con la base en la simple afirmación unilateral y sin prueba alguna del acreedor sobre la existencia de la obligación y, a su vez, la buena fe del deudor se contempla siendo que su oposición torna ineficaz la orden de pago $^{24}$.

Al tenor del Artículo 420 del CGP, dichas afirmaciones, al parecer, divergen de su contenido, por las razones que se exponen a continuación: (a) el Artículo

22 Id. Pág. 31

23 Véase José Alejandro Gómez-Orozco, supra, nota 15. Pág 72.

24 Véase Corte Constitucional de Colombia, supra, nota 3. 
420 del CGP, en el inciso segundo del numeral 6, textualmente establece: "El demandante deberá aportar con la demanda los documentos de la obligación contractual adeudada que se encuentre en su poder. Cuando no los tenga, deberá señalar dónde están o manifestar bajo juramento que se entiende prestado con la presentación de la demanda, que no existen soportes documentales" 25 . Este precepto normativo contiene el verbo deberá, el cual, en su significado elemental, comporta una obligación: la de aportar (en este contexto) los documentos de la obligación. No obstante, como una alternativa al posible incumplimiento de esta primera obligación, y en virtud a que el acreedor no posee los documentos, el precepto citado también obliga al acreedor a manifestar en dónde se encuentran, o bajo la gravedad de juramento manifestar que no existen. En el orden en que se encuentra redactada esta norma, bien puede deducirse que el legislador pensó primero en un proceso monitorio documental, y que ante la imposibilidad de aportar los documentos de la obligación contractual, da paso al proceso monitorio puro, previa manifestación bajo juramento de la no existencia de los mismos por parte del acreedor. (b) De acuerdo con la definición dada por el profesor Calamandrei del proceso monitorio puro como aquel en el que la oposición no motivada del deudor hace caer en la nada la orden de pago, y comparándola con el contenido del Artículo 421 del CGP, en los cuales textualmente se lee:

Si la demanda cumple los requisitos, el juez ordenará requerir al deudor para que en el plazo de diez (10) días pague o exponga en la contestación de la demanda las razones concretas que le sirven de sustento para negar total o parcialmente la deuda reclamada. ${ }^{26}$

\section{Así como:}

Si dentro de la oportunidad señalada en el inciso primero el demandado contesta con explicación de las razones por las que considera no deber en todo o en parte, para lo cual deberá aportar las pruebas en que se sustenta su oposición ${ }^{27}$.

De esta manera, se tiene que el proceso monitorio en Colombia no corresponde al tipo de monitorio puro definido por Calamandrei, dado que el deudor es obligado al oponerse al requerimiento de pago

25 Véase Código General del Proceso (Ley 1564 de 2012). Legis. (2014).

26 Id. Inciso primero.

27 Id. Inciso cuarto. en la contestación de la demanda a que exponga las razones de su oposición y a aportar las pruebas que la fundamenten; contrario a la definición en cita, en la cual en un proceso monitorio solo basta con la oposición sin aducir los argumentos de la misma para que el requerimiento de pago descienda a la nada.

El legislador Colombiano, en el Artículo 420 del CGP, viabiliza el proceso monitorio puro al establecer que el acreedor, con la sola manifestación de la inexistencia de soportes documentales y bajo juramento - que se entiende prestado con la presentación de la demanda-, podrá impetrar el proceso monitorio. Sin embargo, al desarrollar el trámite a seguir en el proceso monitorio, el Artículo 421 del CGP no hizo distinción alguna entre el proceso puro y el documental; esto es, a los dos se les dio el mismo tratamiento procesal.

Dado lo expuesto anteriormente, es posible afirmar - en consonancia con las definiciones de Calamandrei- que en Colombia al entrar en vigencia del CGP, se tendrá por regla general el proceso monitorio documental y no puro. Sin embargo, no es conveniente ser tan exegéticos. Es posible pensar que el legislador introdujo un nuevo tipo de proceso monitorio, en el que se profiere la orden de pago por parte del juez con la sola afirmación unilateral y no probada del acreedor, y a quien se le impartirá el trámite del proceso monitorio documental.

\section{La importancia de la buena de fe del acreedor, las pruebas, el requisito de procedibilidad y las medidas cautelares}

Entre juristas, doctrinantes y operadores jurídicos se han dado grandes discusiones en torno al nuevo proceso monitorio, el cual incursionará en los estrados judiciales una vez entre en vigencia el CGP. Mediante este proceso se garantizará el acceso efectivo a la justicia y el derecho de crédito ${ }^{28}$ de aquellos acreedores

28 "La propiedad es, históricamente, el primero de los derechos subjetivos; el derecho subjetivo nace como propiedad. Pero a medida que progresa el ordenamiento jurídico, surgen otros derechos subjetivos, tanto en el ámbito de la propiedad misma como fuera de ella. El más importante de tales progresos atañe a la constitución del derecho al crédito, al lado del derecho de propiedad. El derecho de propiedad es, para explicarme de algún modo, el derecho sobre la cosa propia, mientras que el derecho de crédito tiene por objeto la cosa ajena. El nacimiento de un derecho sobre la cosa ajena, que a primera vista parece absurdo, se vincula con el problema de la sanción civil, al que recientemente nos hemos referido. Supongamos que el ladrón, habiendo consumido la cosa robada, no esté en condiciones de restituirla; ¿será esta una buena razón para que no tenga él que dar al propietario alguna cosa, en 
de obligaciones en dinero de mínima cuantía que, por carecer de un título ejecutivo que la contenga, podrán hacerlo exigible de manera célere y eficaz, soslayando las formalidades procedimentales que hacen de larga duración, un proceso judicial ${ }^{29}$.

1. Breve discurrir acerca del requerimiento de pago y mandamiento de pago

Al abordar la definición etimológica que reseña Colmenares ${ }^{30}$ del vocablo monitorio, se deduce que su significado corresponde a "amonestación", "aviso" o "advertencia". A reglón seguido, este autor precisa que en el Derecho europeo, uruguayo y venezolano, el significado de monitorio es similar al que se tiene en Italia: "advertencia", "apercibimiento" o "requerimiento" 31 .

La Real Academia Española define el término mandamiento así: "1. m. Precepto u orden de un superior a un inferior; $2 . \mathrm{m}$. Cada uno de los preceptos del decálogo y de la iglesia; 3. m. Der. Despacho del juez, por escrito, mandando ejecutar algo.

Si se comparan los dos términos es evidente una diferencia etimológica entre los mismos, razón por la cual, en el contexto jurídico colombiano, es importante considerarlo. Esto en la medida en que el mandamiento de pago es el término que estableció el legislador para nombrar la primera providencia que el juez emana en un proceso de ejecución que se ha admitido. Este mandamiento de pago da a entender al ejecutante que su título reúne las condiciones para ser ejecutado, esto es, claro, expreso y exigible, y que además comporta un mandato u orden de pago. Al

compensación de lo que le quitó? He aquí como, al lado de la restitución, se constituye otra forma de sanción civil, que es el resarcimiento del daño. Al robado debe restituirle el ladrón la cosa robada y si la restitución no vale para reconstituir la situación tal como era con anterioridad, tiene que darle además de las cosas suyas, hasta el límite del daño sufrido por aquel. De ahí surge un derecho, no ya solo sobre las cosas propias, sino también sobre las cosas ajenas, al cual se da el nombre de derecho de crédito. Aquí está en germen un instituto jurídico que, con el progreso de la sociedad y la complejidad cada vez mayor de las relaciones económicas, ha asumido en el derecho moderno un prodigioso desarrollo, al punto de que la importancia del derecho de crédito ha terminado por sobrepasar hoy la del derecho de propiedad". Véase Francesco Carnelutti. Cómo nace el Derecho. Temis s.A. (2008). Págs. 38-39.

29 Cf. Corte Constitucional de Colombia, supra, nota 3.

30 Véase Carlos Colmenares. "El procedimiento monitorio en Colombia”. El proceso monitorio en América Latina. PASAdo, PRESEnTE y FUturo. Temis. (2013). Pág. 109.

31 Indica Colmenares que en el Derecho europeo el término monitorio se utiliza al igual que inyunción; así como que en Uruguay se utiliza la expresión estructura monitoria, y en Venezuela intimación. Id. deudor, ante un mandamiento de pago en su contra, le asiste el derecho, en su oportunidad procesal, de interponer recurso de reposición con el fin de intentar dejarlo sin efectos. Adviértase que esta providencia podrá notificarse, en su orden, personalmente y por aviso o edicto. De igual forma, no solo se profiere en procesos ejecutivos por obligaciones de dar, sin límite de cuantía, sino también en aquellos que versan sobre obligaciones de hacer y no hacer.

Ahora bien, el término monitorio se introduce en la legislación colombiana con el mismo significado etimológico que se le da en los ordenamientos procesales civiles de Italia, Alemania y Francia, entre otros (esto es, el de requerimiento). Luego, se ha de entender que en un proceso monitorio, la primera providencia que emite el juez al encontrar admisible la demanda es un requerimiento de pago. Este requerimiento de pago, en el contexto del proceso monitorio contenido en el CGP, se reviste de características especiales, tales como: 1. Contra este no procede recurso alguno; 2. $\mathrm{Si}$ no existe documento que soporte la obligación, este se profiere con la sola manifestación unilateral que hace el acreedor, condicionada a la gravedad del juramento, el cual se entiende prestado con la presentación de la demanda; 3. Solo se profiere por obligaciones contractuales, dinerarias de mínima cuantía, cuantificable y exigibles; y, 4. Su notificación al deudor debe llevarse a cabo personalmente.

Por consiguiente, no es de recibo que la Corte Constitucional, en la sentencia C-726/14, mediante la cual declara exequibles los Artículos 419 y 421 de la Ley 1564 de 2012, indistintamente y en varias oportunidades se refiera al requerimiento de pago como una orden pago. Dicho de paso, la afirmación que hace la Corte en el numeral 6.4 de la sentencia en cita, en relación a que el requerimiento de pago debe ser notificado personalmente - sin que sea posible la notificación por aviso-, contradice el contenido de las normas acusadas.

2.Incidencia de la buena fe del acreedor, al proferirse el requerimiento de pago en el proceso monitorio puro

Del Artículo 419 del CGP se colige cómo aquella de la que se pretende su pago en dinero, debe ser de origen contractual, determinada, exigible y de mínima cuantía. Luego, la procedibilidad o admisión de la demanda monitoria estará sujeta al análisis que haga el juez de la información registrada por el acreedor en los formatos dispuestos y prediseñados por el Consejo Superior de la Judicatura para tal fin. 
En un proceso monitorio documental en el que el acreedor ha aportado el documento que contiene la obligación, el trabajo de análisis del juez no requiere de mayor esfuerzo, ya que el documento aportado se constituye en el pilar que le sustenta la decisión de proferir el requerimiento de pago. Sin embargo, no ocurre lo mismo cuando se trata de un proceso monitorio que se impetra con la sola afirmación unilateral del acreedor - bajo la gravedad de juramento- de que no existe documento alguno que soporte la obligación (monitorio puro). En este caso se requiere de la ardua tarea del juez para encontrar los elementos que debe contener la obligación de la que se persigue su pago, a fin de que se admita la demanda monitoria y se profiera el requerimiento de pago. Dicho de otra forma, no es tarea fácil para el juez, en el proceso monitorio puro, encontrar que la obligación es contractual y exigible para proceder a la admisión. En este punto, el juez tendrá que fundamentar la emisión del requerimiento de pago en la buena fe del acreedor.

No obstante, del relato que haga el acreedor de los hechos, el juez podrá encontrar el origen contractual de la obligación. Sin embargo, lo mismo no ocurrirá con la misma probabilidad de acierto con relación a la exigibilidad. En el contexto jurídico, se tiene que una obligación es exigible cuando no se halla sujeta a una condición de plazo, de manera que el juez tendrá que cerrar los ojos y proferir el requerimiento de pago con fundamento en la buena fe del acreedor.

Recobra importancia este análisis cuando el deudor debidamente notificado de un proceso monitorio puro omite el requerimiento de pago al guardar silencio por razones ajenas a su voluntad, como es el caso fortuito o la fuerza mayor, $y$, en consecuencia, el juez dicta la sentencia a que se refiere el Artículo 421 del CGP y luego procede con la ejecución. De este modo, se deja en lo más profundo y oculto de la decisión la incertidumbre de si en verdad la obligación era contractual y exigible.

Algo parecido ocurrirá cuando frente a un proceso monitorio puro el deudor se opone al requerimiento de pago, y argumenta - sin aportar prueba alguna de su afirmación-que no debe la obligación, en razón a que esta jamás ha existido o dejó de existir. En este caso es necesario traer a colación la aclaración de voto a la Sentencia C-726/14 que hiciera el magistrado Mendoza-Martelo, quien consideró desproporcionado:

Que se exija al supuesto deudor pruebas de la razones por las que no debería la suma reclamada, mientras que el actor no afronta una carga semejante, más aún cuando se trata de una negación indefinida, escenario en el que suele invertirse la carga de la prueba"32.

3. La relevancia de otras pruebas no documentales en el proceso monitorio puro

Al partir de la afirmación que se hace en párrafos anteriores (como al proceso monitorio puro en Colombia se le da el mismo trámite procesal que al documental), se tiene que, en un proceso monitorio puro, al tenor del Artículo 420 del CGP, la demanda que promueve el acreedor deberá contener las pruebas que pretenda hacer valer, incluidas las solicitadas para el evento en que el demandado se oponga; y conforme al Artículo 421, inciso cuarto, el demandado debe aportar las pruebas en que sustenta su oposición a deber todo o en parte. Estos preceptos normativos forjan el siguiente interrogante: En un proceso monitorio puro, ante la inexistencia del documento que contiene la obligación contractual, ¿qué tipo de pruebas pueden hacer valer las partes a fin de soportar su pretensión u oposición en el proceso monitorio puro? Pues bien, el CGP, en el Artículo 165, enuncia una amplia gama de medios de prueba, tales como la declaración de parte, la confesión, el juramento, el testimonio de terceros, el dictamen pericial, la inspección judicial, los documentos, los indicios, los informes y cualquiera otros medios que sean útiles para la formación del convencimiento del juez. Todas podrán solicitarse y aportarse en el proceso monitorio, en la medida en que resulten ser conducentes, pertinentes y útiles. Sin embargo, el CGP reviste al juez de la facultad de practicar pruebas no previstas en este código, preservando los principios y garantías constitucionales.

Lo anterior significa que el juez, en un proceso monitorio puro, en aras de proferir una sentencia en la cual acceda a las pretensiones o las deniegue, en razón a que las sentencias inhibitorias han quedado proscritas en el $\mathrm{CGP}^{33}$, tendrá que desarrollar su

32 Véase Corte Constitucional de Colombia. Comunicado N. ${ }^{\circ} 38$ (septiembre 24 del 2014). Disponible en http://www.corteconstitucional.gov.co/comunicados/No.\%2038\%20comunicado\%2024\%20 de\%20septiembre\%20de $\% 202014$.pdf

33 "La experiencia del proceso, sobre todo, enseña, aun al gran público, que las pruebas no son a menudo suficientes para que el juez pueda reconstruir con certeza los hechos de la causa. Las pruebas deberían ser como faros que iluminaran su camino en la oscuridad del pasado; pero frecuentemente ese camino queda en sombras. ¿Qué hace en tales casos? Es necesario juzgar. Pero es esta una situación sumamente penosa: no se puede pronunciar una condena penal contra alguien sin estar ciertos de su culpabilidad, ni 
creatividad en el momento de decretar las pruebas que lo conduzcan a la verdad, así como perfeccionar aún más su técnica para el interrogatorio de las partes y de los testimonios. Labor del juez que requiere tiempo y dedicación en un proceso monitorio puro, en el cual se adolece de la prueba documental que contiene la obligación, la cual durante mucho tiempo fue prueba fundamental en el proceso civil ${ }^{34}$.

Es precisamente con relación a este punto que es importante citar a Parra-Quijano ${ }^{35}$ :

Además, el proceso civil colombiano no es, ni tampoco lo será con el Código General del Proceso, un proceso totalmente de partes: existen las pruebas de oficio y, por sobre todo, el artículo $4^{\circ}$ del Código General del Proceso muestra una ideología muy clara: "El Juez debe hacer uso de los poderes que este código le otorga para lograr la igualdad real de las partes".

4. El acertijo del requisito de procedibilidad en el proceso monitorio puro

La ley 640 de 2001, por medio de la cual se modificaron normas relativas a la conciliación, introdujo

condenarlo a que pague una deuda sin estar ciertos de que es deudor; pero es igualmente injusto también absolverlo sin la certeza de que no haya cometido el delito o de que no hubiera contraído la deuda. En todo caso, en el supuesto de incertidumbre, se corre el riesgo de cometer una injusticia. Son estos los casos en que el proceso fracasa en su objeto". Véase Francesco Carnelutti. CóMO SE HaCE Un Proceso. Temis s.A. (2007). Pág. 62-63.

$34 \mathrm{Al}$ respecto, Carnelutti afirma: "Dicho en términos empíricos, el testigo es una persona, y el documento es una cosa que narra. El notario forma el documento mientras alguien le declara su voluntad; el testigo forma el testimonio mientras el juez lo escucha: en el primer caso está presente el declarante, pero está ausente el juez; en el segundo ocurre lo contrario: está presente el juez, pero está ausente la persona cuyo testimonio refiere la declaración. Este criterio distintivo aclara los méritos y deméritos de cada uno de estos dos tipos de representación: el documento garantiza la fidelidad de las pruebas, en particular protege de los peligros de infidelidad de la memoria del hombre; pero por otra parte, el testimonio puede adaptarse con más ductilidad a las exigencias del juez, las cuales, en el momento en que se forma el documento, pueden no estar del todo previstas. Y ya hemos indicado la razón por la cual el documento sirve perfectamente en orden al proceso civil y el testimonio en orden al proceso penal. En este último los hechos que hay que certificar son típicamente hechos ilícitos, que en la mayoría de los casos se sustraen a la documentación, mientras que en el proceso civil se comprueba que son frecuentemente actos lícitos, contratos, acuerdos, testamentos y similares, que por lo común en el momento del mismo en que se realizan son documentados, bien por las partes mismas que lo realizan, bien por un documentador público, en particular por un notario”. Id. Pág. 58-59.

35 Véase Jairo Parra Quijano. "Prólogo". El Procedimiento monitorio en América Latina. Pasado, presente y futuro. Temis. (2013). Pág XI. la conciliación pre-procesal como requisito de procedibilidad para promover el proceso declarativo, a excepción de los procesos declarativos especiales de expropiación y el divisorio. Su inobservancia se constituye causal de inadmisión de la demanda. No obstante, la misma ley indica como en aquellos casos en los cuales la demanda deba dirigirse contra personas indeterminadas o se ignore de alguno de los demandados su paradero, no es exigible demostrar que se intentó la conciliación como requisito de procedibilidad $^{36}$.

En torno al tema de la acreditación, de haber agotado el intento de conciliación pre-procesal a fin de impetrar un proceso monitorio puro o documental por parte del demandante, se han dado muchos debates. En estos, tanto juristas como doctrinantes han tomado caminos diferentes. Algunos consideran que no es exigible este requisito en el monitorio, pues resultaría ilógico y contrario al espíritu normativo; otros, contario sensu, afirman que al tenor de la Ley 640 del 2001, se debe acreditar su cumplimiento.

Así, surge entonces el siguiente interrogante, ¿es exigible o no, haber agotado el intento de conciliación pre-procesal a fin de impetrar el proceso monitorio? A esta cuestión se puede responder a partir de los siguientes silogismos:

P1: La Ley 640 de 2011 establece el requisito de procedibilidad en los procesos declarativos, excepto en los procesos especiales de expropiación y divisorio.

$\mathrm{P} 2$ : El proceso monitorio es un proceso declarativo especial.

C: La Ley 640 de 2011 establece el requisito de procedibilidad para el proceso monitorio.

Si este silogismo no es suficiente para soportar la afirmación de la exigibilidad del requisito de procedibilidad en el proceso monitorio, es posible entonces construir otro silogismo, el cual llevará a la misma conclusión, con las siguientes premisas:

P1: La Ley 640 de 2011 no exceptúa del requisito de procedibilidad a los procesos declarativos en los cuales no se demande a indeterminados.

P2: El monitorio es un proceso declarativo en el cual no se demanda a indeterminados (en razón a que la misma se debe notificar personalmente al demandado).

36 Véase Ley 640 de 2001. Por la cual se modifican normas relativas a la conciliación y se dictan otras disposiciones. Enero $24 \mathrm{de}$ 2001. Do 44.303. Artículo 38. Véase también Ley 1564 del 2012, supra, nota 2. Artículo 621. 
C: la Ley 640 de 2011 no exceptúa del requisito de procedibilidad al proceso monitorio.

Por consiguiente, la respuesta al interrogante formulado es: sí debe agotarse el requisito de procedibilidad para iniciar el proceso monitorio, mientras no exista norma en contrario.

Es oportuno ahora citar la afirmación de Rojas $^{37}$ en relación con el futuro del requisito de procedibilidad:

Tal vez no sobre reiterar que como es innecesario agotar el intento de conciliación para acudir al juez cuando se solicite la práctica de medidas cautelares (CGTP, art. 590 par. $1^{\circ}$ ), y éstas caben prácticamente en todos los procesos declarativos, seguramente no subsistan muchos casos en los que sea exigible dicho intento.

De la anterior afirmación podemos deducir que en el proceso monitorio podrá sustituirse el agotamiento del requisito de procedibilidad con la solicitud de una medida cautelar. Esta afirmación genera una nueva controversia, dado que podría entenderse que basta con la mera solicitud de la medida para suplir el requisito de agotamiento del intento de conciliación pre-procesal, lo cual no es cierto. El término solicitar va más allá de la simple acción de pedir; quiere decir que la medida debe ser procedente y decretable y, para que aquella sea decretable, tendrá el juez que valorar la existencia del fumus bonis iuris, lo que en el proceso monitorio puro exige de un gran trabajo de análisis por parte del operador jurídico, teniendo en cuenta que al momento de la admisión de la demanda no se tiene un documento que contenga la obligación. El operador jurídico tan solo dispone de un relato de hechos y de unas pruebas solicitadas o a decretar de oficio, las que se practicaran en el trámite de verbal sumario que se le imprime al proceso, en caso de oposición por el deudor.

5. Realidad de las medidas cautelares en el proceso monitorio puro

La procedencia y el decreto de medidas cautelares en el proceso monitorio puro también genera controversia. Veamos cómo las medidas cautelares cobran gran importancia en los procesos, tanto declarativos, como ejecutivos, hasta el punto que el CGP las

37 Véase Miguel Enrique Rojas Gómez. LeCCiones DE DERECHO procesal. Tomo II, Procedimiento Civil. esaju. 2013. Pág. 249. reconoce como un instrumento para garantizar que la tutela judicial sea efectiva. ${ }^{38}$

El nuevo ordenamiento procesal civil ofrece variedad en medidas cautelares, las cuales se pueden clasificar en reales y personales, nominadas e innominadas, y conservativas e innovativas, dependiendo del criterio que se aplique. Estos criterios son presupuestos sustanciales de las medidas cautelares: el peligro de la demora (periculum in mora), la apariencia del buen derecho (fumus boni iuris), la razonabilidad y proporcionalidad. ${ }^{39}$

En el parágrafo del Artículo 422 del CGP, el legislador estableció que en los procesos monitorios podrán practicarse las medidas cautelares previstas para los demás procesos declarativos. Este precepto normativo remite al Artículo 590 del mismo estatuto procesal, que será la base para resolver el siguiente interrogante: ¿Cuáles son las medidas cautelares que proceden para garantizar la tutela judicial efectiva en el proceso monitorio?

El Artículo 590 del CGP establece las reglas para la solicitud, el decreto, la práctica, la modificación, la sustitución o la revocatoria de las medidas cautelares. En cuanto al decreto de las medidas cautelares, establece que procede: (a) la inscripción de la demanda sobre bienes sujetos a registro y el secuestro de los demás cuando la demanda verse sobre dominio u otro derecho real principal, directamente o como consecuencia de una pretensión distinta o en subsidio de otra, o sobre una universalidad de bienes. Lo que quiere decir que en un proceso monitorio puro no procede la inscripción de la demanda en bienes sujetos a registro y el secuestro de los demás, dado que el proceso monitorio versa sobre obligaciones contractuales, exigibles y dinerarias, y no sobre asuntos que versen sobre el dominio u otro derecho real principal; (b) la inscripción de la demanda sobre bienes sujetos a registro que sean de propiedad del demandado, cuando en el proceso se persiga el pago de perjuicios provenientes de responsabilidad civil contractual o extracontractual. Igualmente, resulta inaplicable en el proceso monitorio, en razón a que este no fue creado para declarar responsabilidad alguna en asuntos contractuales y menos extracontractuales; (c) Cualquier otra medida que el juez encuentre razonable para la protección del derecho objeto del litigio, impedir su infracción o evitar las consecuencias derivadas de la misma, prevenir daños, hacer cesar los que se hubieren causado o asegurar la efectividad de la pretensión. Y es exactamente en esta regla en la que se

\footnotetext{
38 Id. Pág 438.

39 Id. Pág 439.
} 
exige del demandante y del juez mayor creatividad, a fin de pedir y decretar, respectivamente, una medida cautelar diferente a las anteriores, denominadas las medidas cautelares innominadas.

En cuanto a esta última regla, es necesario hacer un análisis un tanto más profundo frente al proceso monitorio. Partiendo de la afirmación según la cual la finalidad del proceso monitorio es la tutela judicial efectiva y la protección del derecho de crédito mediante la creación del título ejecutivo, resultaría inocuo obtener una sentencia si no se tiene una medida cautelar que asegure la ejecución de la misma; esto es, la inscripción de la demanda en bienes sujetos a registro o el secuestro de bienes muebles, como ocurre en el proceso ejecutivo propiamente dicho. Encontrar una medida innominada en el contexto del proceso monitorio, en aras de garantizar la efectividad del derecho al crédito, será una ardua tarea.

Desvanece un tanto más la materialización del derecho al crédito de los acreedores en el proceso monitorio la exigencia, contenida en el numeral 2 del Artículo 590 de CGP, para el acreedor peticionario de la medida cautelar, de prestar caución equivalente al $20 \%$ del valor de las pretensiones estimadas, esto es, el monto de obligación reclamada en dinero y de los intereses causados.

La caución judicial es la garantía que debe otorgarse con el fin de amparar las costas y perjuicios derivados de la práctica de medidas cautelares. El Artículo 603 del CGP establece que estas podrán ser reales, bancarias u otorgadas por compañías de seguros, en dinero, títulos de deuda pública, certificados de depósito a término o títulos similares constituidos en instituciones financieras.

En el escenario del proceso monitorio - que en palabras de la Corte Constitucional se constituye en una medida de acceso a la justicia para acreedores de obligaciones dinerarias que no acostumbran documentar sus créditos en títulos ejecutivos, y que, dado lo complicado que resulta acudir a un proceso judicial complejo y demorado, desisten de su cobro- ${ }^{40}$, estas cauciones resultan no ser asequibles al pequeño acreedor o ciudadano de a pie, en quien se pensó al crear el proceso monitorio en Colombia. Así, la caución más común en los procesos judiciales es la otorgada por las compañías de seguros, y en este punto surge un nuevo interrogante: ¿Están dispuestas las compañías aseguradoras a expedir la caución, sin mayor exigencia al pequeño acreedor, en un proceso monitorio puro, en el que no existe prueba documental de la obligación pretendida en dinero? Este interrogante despierta

40 Véase Corte Constitucional de Colombia, supra, nota 3. gran interés cuando recordamos que mediante el proceso monitorio, tanto puro como documental, podrá reclamarse el pago de obligaciones hasta por 40 salarios mínimos mensuales, que a la fecha equivale más o menos a 27 millones de pesos, suma que entre los ciudadanos de a pie representa una alto porcentaje, sino es todo o más que su patrimonio. De lo dicho se deduce que si el acreedor no puede prestar la caución, no podrá solicitar medidas cautelares, de manera que deberá agotar el intento de conciliación pre-procesal a fin de acreditar el requisito de procedibilidad ${ }^{41}$.

Al final de este discurrir académico en torno al proceso monitorio es claro que no son suficientes los matices en análisis para restarle importancia al proceso que da acceso a la justicia al "pequeño comerciante, el vendedor de cosas de segunda mano, para el tendero de regular tamaño, etc." ${ }^{\text {+2 }}$ ); el cual será, además, el proceso estelar del CGP.

\section{CONCLUSIONES}

El CGP es el vehículo que permitirá alcanzar la eficacia en la administración de justicia que tanto anhelan los colombianos. Especialmente en lo concerniente al acceso a la justicia, a la tutela judicial efectiva, al derecho al crédito y a las garantías del debido proceso.

El proceso monitorio en Colombia no corresponde a la clase de monitorio puro, en los términos que Calamandrei lo caracterizó, contrario a lo que afirman algunos doctrinantes y autores. El legislador introduce inicialmente el proceso monitorio documental, sin embargo, da paso a un monitorio puro en el evento en que el acreedor no aporte pruebas documentales de la obligación contractual pretendida en dinero. No obstante, tanto documental como puro, tendrán el mismo tratamiento procesal. Lo que permite deducir que el legislador ha creado un nuevo tipo de proceso monitorio, un híbrido entre puro y documental.

\footnotetext{
41 "En el caso en que la Ley permite pedir la medida cautelar con la presentación de la demanda y en esta se hace evidente dicha solicitud, aquella no podrá rechazarse ni inadmitirse por no haber otorgado el requisito de procedibilidad de intentar conciliar en un centro extrajudicial en derecho, pues así lo dispone el parágrafo primero del artículos 590 de la Ley 1564 de 2012. Se lee en dicho parágrafo: "En todo proceso y ante cualquier jurisdicción, cuando se solicite la práctica de medidas cautelares se podrá acudir directamente al juez, sin necesidad de agotar la conciliación prejudicial como requisito de procedibilidad". Véase Jorge Forero Silva. Medidas CaUtelares EN EL CóDigo GENERAL DEL PROCESO. Temis. (2013). Pág. 20.

42 Véase Jairo Parra Quijano, supra, nota 36. Pág. XI.
} 
Un mandamiento de pago nos indica la admisión de un proceso ejecutivo, mientras que un requerimiento de pago la de un monitorio, con fundamento en la buena fe del acreedor.

En un proceso monitorio puro, ante la inexistencia del documento que contenga la obligación contractual exigible al deudor, tendrá el juez que acudir a las facultades que le otorga el CGP en lo relativo a la potestad para decretar pruebas de oficio y todas aquellas que a bien considere necesarias en el propósito de encontrar la verdad, pues no podrá dejar de fallar, en virtud a que han quedado proscritas las sentencias inhibitorias.

Al tenor de las normas relativas a la conciliación pre-procesal, con el fin de iniciar un proceso monitorio clasificado como declarativo especial, el demandante deberá acreditar el cumplimiento del requisito de procedibilidad, esto es, aportar prueba de haber agotado el intento de conciliación. No obstante, podrá suplir este requisito con la solicitud y lógicamente con la procedencia de una medida cautelar, para lo cual tendrá que prestar caución. Esta medida cautelar será de tipo innominada, pues no proceden las propias del proceso ejecutivo, como tampoco la de inscripción de la demanda en bienes sujetos a registro, ni el secuestro de otros bienes. En fin, encontrar una medida innominada en el contexto del proceso monitorio, en aras de garantizar la efectividad del derecho al crédito, será una tarea ardua.

\section{Agradecimiento}

Finalmente, exalto la valiosa colaboración y participación de los estudiantes de pregrado, integrantes del semillero de procesal civil de la Universidad Cooperativa de Colombia, sede Bucaramanga: Adriana Carolina Ardila-Suárez, Carlos Andrés Niño-Sanabria, José Vicente Quintero-Martínez, Laura Margarita Sánchez-Villalobos, Lili MedinaOrtiz, Manuel Fernando Gómez-Becerra, Sergio Augusto Díaz-Suárez, Tatiana Ardila-Sánchez y Yimer Camacho-Mesa. Ellos, con gran entusiasmo, participaron en la recolección y análisis de la información relacionada con el proceso monitorio para la construcción de la ponencia presentada en el marco del xvi Concurso Internacional de Semilleros de Derecho Procesal 2015, promovido por el ICDP en Pereira.

\section{REFERENCIAS}

Abelardo Poveda. Manual del proceso monitorio. MoDelo documental español. Ediciones del Profesional Ltda. (2006).

Carlos Colmenares. "El procedimiento monitorio en Colombia”. El PROCESO MONITORIO EN AMÉRICA LATINA. PAsado, Presente y futuro. Temis. (2013).

Código General del Proceso (Ley 1564 de 2012). Legis. (2014).

Corte Constitucional de Colombia. Comunicado N. ${ }^{\circ} 38$ (septiembre 24 del 2014). Disponible en http://www. corteconstitucional.gov.co/comunicados/No.\%20 $38 \% 20$ comunicado\%20 24\%20de\%20septiembre $\% 20$ de\%202014.pdf

Corte Constitucional de Colombia. Sentencia C-726/14. (MP Martha Victoria Sáchica Méndez, SEPtiemBRE 24 DEL 2014).

EurLex. "Reglamento de la Unión Europea”. Disponible en http://europa.eu/ legislation_summaries/justice_freedom_security/judicial_cooperation_in_ civil_matters/116023_es.htm

Francesco Carnelutti. Cómo SE HACE UN PROCESO. Temis S.A. (2007).

Francesco Carnelutti. Cómo NACE EL Derecho. Temis s.A. (2008).

Instituto Colombiano de Derecho Procesal. Proyecto DE Código General del Proceso, Exposición de MoTIvos. Disponible en http://www.icdp.org.co/ descargas/cgp/ExposicionMotivos.pdf

Joan Picó i Junoy. El Proceso MONITORIO UNA VISIÓn ESPAÑOLA Y EUROPEA DE LA TUTELA RÁPIDA DEL CRÉDITO. Disponible en http://www.icdp.org.co/revista/ articulos/ 37/JoanPicoIJunoy.pdf

Jordi Nieva-Fenoll. Aproximación al origen del procedimiento monitorio. EL PROCEDIMIENTO MONITORIO EN América Latina. Pasado, Presente y futuro. Editorial Temis. (2013). Págs. 2-16.

Jairo Parra-Quijano. "Prólogo”. El PRocedimiento Monitorio en América Latina. PASAdo, Presente y fUTURo. Temis. (2013). Pág XI.

José Alejandro Gómez-Orozco. InTroducción AL PROCESO MONITORIO COLOMBIANO. CONSTITUCIONALIDAD Y ORALIDAD DEL DERECHO CIVIL. Librería Jurídica Sánchez R. Ltda. (2014). Pág. 56.

Jordi Nieva-Fenoll. Aproximación al origen del procedimiento monitorio. EL PROCEDIMIENTO MONITORIO en América latina. Pasado, presente y futuro. Temis. (2013). 
Juan Pablo Correa-Delcasso. El proceso monitorio en el derecho comparado: diez puntos clave para su correcta implementación y desarrollo en los países de América Latina. El PRocedimiento Monitorio en AmÉricA Latina. Pasado, presente y futuro. Temis. (2013). Págs.17-55.

Ley 640 de 2001. Por la cual se modifican normas relativas a la conciliación y se dictan otras disposiciones. Enero 24 del 2001. Do 44.303

Ley 1564 de 2012. Por medio de la cual se expide el Código General del Proceso y se dictan otras disposiciones. Julio 12 del 2012. Do 48489.
Miguel Enrique Rojas-Gómez. Lecciones de Derecho procesal. Tomo II, Procedimiento Civil. esaju. 2013.

Red Judicial Europea en Materia Civil y Mercantil. Guía PRÁCTICA PARA LA APLICACIÓN DEL REGLAMENTO relativo al proceso monitorio europeo. Pág. 6, Disponible en http://ec.europa.eu/civiljustice/publications/docs/guide_european_ enforcement_order_es.pdf 